\title{
Analysis of Microbe's from Municipal Waste Water (Pond) and Uses the Microbes for the Application of Waste Water Treatment
}

\author{
Zeynu Shamil Awol, Rezika Tofike Abate \\ Department of Chemical Engineering, College of Engineering and Technology, Wolkite University, Wolkite, Ethiopian
}

Email address:

Zeynu2006@gmail.com (Z. S. Awol)

\section{To cite this article:}

Zeynu Shamil Awol, Rezika Tofike Abate. Analysis of Microbe's from Municipal Waste Water (Pond) and Uses the Microbes for the Application of Waste Water Treatment. Chemical and Biomolecular Engineering. Vol. 6, No. 2, 2021, pp. 37-42.

doi: $10.11648 /$ j.cbe. 20210602.12

Received: April 29, 2021; Accepted: July 10, 2021; Published: July 21, 2021

\begin{abstract}
Water contamination was a serious problem throughout the world. Various technologically advanced treatment methodologies for example activated sludge process, membrane bioreactor, trickling filter, rotating biological contractor and oxidation ditch are widely studied well documented and adopted in practice. However, attention to promising low-investmentcost technologies such as slow biological waste water treatments after preliminary/primary treatment techniques was quite effective water treatment technology. It is also efficient in removing coli form microorganisms such as Cryptosporidium, E. coli and bacteriophage from wastewater. Apart from reduction of pathogenic load which is ascribed to the biological processes. This way of technology adopted the methodology taking the sample in the field of water surface two parts in sampling pond water in the surface pond water and inner parts also handling two different glass bottles. Then in analysis their analysis the sample subjected to physiochemical analysis then again the sample subjected to serial dilution to identify the microbe's spp in the water sample (surface and deepest) part of pond water surface part of sample more microbes familiar conducted in this experiment. Then by using those identified microbes dosing this is done using $10^{-6}$ and $10^{-5}$ by prepared nutrient agar $(3.25$ gram with $250 \mathrm{ml}$ of distilled water). Then take $1 \%(0.5), 3 \%(1.5)$ and $5 \%(2.5)$ by volume of broth added into waste water of $49.5 \mathrm{ml}, 48.5 \mathrm{ml}$ and $47.5 \mathrm{ml}$ respectively. This means that for $50 \mathrm{ml}$ of conical flask as the colonies of culture increase the probability of waste water to be clear was too been high so 47.5 with $5 \%$ (2.5) combined form of broth high potent of cleaned.
\end{abstract}

Keywords: Physiochemical Analysis, Biological Waste Water Treatment, Microbial Analysis, Pond Water, Nutrient Agar

\section{Introduction}

Waste water is any water that has been adversely affected in quality by anthropogenic influence. Wastewater can originate from a combination of domestic, industrial, commercial or agricultural activities. [16, 9] The socio political and industrial corner of Ethiopia, the capital city Wolkite for gurage zone SNNP regional state of Ethiopia generates high amount of wastewater from municipal and industry $[13,10]$.

Sewage is a type of wastewater that comprises domestic wastewater which is contaminated with urine from people's toilets and other sources such as, surfactants, personal care products and others, and can cause series problems to the community if not treated properly [13]. The seasonal and perennial rivers and groundwater reserves of Addis Ababa are polluted with different organic and inorganic pollutants by industrial and municipal solid and liquid wastes. The polluted river water for example Akaki Kaliti is used by downstream residents to grow vegetables, which are sold and consumed by inhabitants of the city.

There may be nitrate or other endocrine disrupting substances in this waste water that comes from toilet or other the sources. [12, 15] Beyond the necessary limit of this compound is not well for plant even it can cause potential health hazards to infants and pregnant women or may be the cause for infertility $[4,6]$.

More of the communities dispose the waste from the 
house into pond. [17, 8] If it is not properly cleaned, water can carry disease. Since we live, work and play so close to water, harmful bacteria have to be removed to make water safe $[6,21,19]$.

\subsection{Aseptic Technique}

An aseptic technique refers to protocols and procedures you use to insure that no microbes contaminate your experiment and that the microbes you are working with do not contaminate you, your colleagues, or working environment. Because microorganisms are ubiquitous, you need to assume that every environment is replete with them. For this reason disinfectant and laminar flow biological safety cabinet is used [11].

When using laminar flow biological safety cabinet, all the sterilized materials will be putted on cabinet and then close the door. Then open UV light without opening fan for at least 5 min. lastly close the UV light and open the door \& start doing your work by opening fan [20].

\subsection{Work Area Disinfection}

Before beginning any laboratory experiment, you must spray down the lab bench with a surface disinfectant. A large portion of the disinfectant's ability to kill microbes is based on contact with the microbe itself. You must repeat this procedure at the end of every laboratory session $[3,7,23]$

\subsection{Transfer Instruments- Loops and Needles}

Wire loops and needles are made from inert metals such as platinum. They are extremely durable and can be sterilized by incineration. To do this, place the loop or needle into the flame of a Bunsen burner (the hottest portion is in the blue flame). Allow the loop or needle to get red hot, and then remove. [20] Make sure the transfer instrument is cool before inserting into a culture for inoculation. You will do this prior to any inoculation and after any inoculation $[22,21,18]$.

\subsection{The Main Objective}

This experiment is aimed to identify the types of microorganisms that are found in municipal waste water, and inoculate the cultivated microorganism and use them for the waste water treatment.

\section{Methodology}

Before starting our experiment any equipment should be sterilized in aseptic.

\subsection{Sample Preparation}

The waste water from SNNPR regional state of Ethiopia guraga zone town of wolkite kara sefer specific area jeblow meda pond water was collected from surface \& deep of pond, and was transferred to lab using two glass bottles for analysis.

\subsection{Characterization (Analysis) of Parameter}

Water quality parameters include chemical, physical, and biological properties and can be tested or monitored based on the desired water parameters of concern. Parameters that are frequently sampled or monitored for water quality including measures of the following water quality characteristics or parameters:

1) Temperature: air temperature \&water temperature.

2) dissolved oxygen (oxygen in water)

3) $\mathrm{PH}$.

4) TDS

5) Conductivity and chloride.

6) Turbidity.

7) Water level.

8) precipitation (one site)

9) $\mathrm{BOD}_{5}$

10)COD

11)Other chemical/physical analysis should be determined

\subsection{Spread Plate Techniques}

A variety of techniques has been developed for the isolation of microorganism, mainly the bacteria, from the specimen or from the sample cultures. $[14,5]$ The spread plate method is a technique to plate a liquid sample containing bacteria so that the bacteria are easy to count and isolate. A successful spread plate will have a countable number of isolated bacterial colonies evenly distributed on the plate. Spread plate culture technique is among the most widely used culture technique for isolating the bacteria $[1-3,20]$.

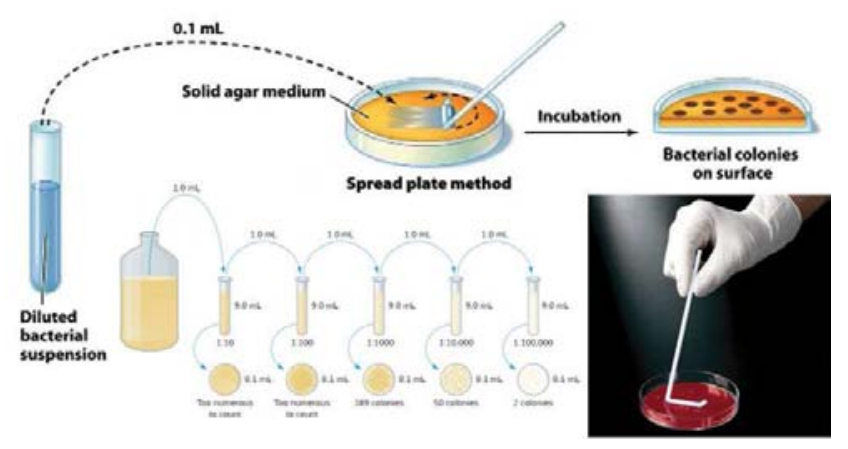

Figure 1. Serial dilution.

In this technique, a serially diluted specimen containing 2 or more bacteria or microbe (Mixed culture) is used which is spread over the solidified agar media plates as a thin layer with the help of a sterile L-shape glass rod (Spreader) while the media plate is spun on a turntable.

The principle behind this method is that when the Media plate is spun, at some stage, single cells will be deposited with the bent glass rod (Spreader) onto the surface of the Agar media. Some of the cells present in the specimen/ diluted specimen will be separated from each other by a distance sufficient to allow the colonies that develop to be free from each other. 


\subsubsection{Serial Dilution}

1) The sterilized distilled water was then cooled.

2) $1 \mathrm{ml}$ of samples for deep and surface were taken and added into cooled $9 \mathrm{ml}$ distilled water of two test tube (two $10^{-1}$ ) using pipette to dilute the sample.

3) Then $1 \mathrm{ml}$ droplet of solution was taken from each of the $1^{\text {st }}$ test tube, and added to each $2^{\text {nd }}$ test tube.

4) This procedure was continued up to the $9^{\text {th }}$ test tube of sterilized distilled water for each sample (i.e., you make $10^{-1}-10^{-9}$ dilution for each sample) one after the other.

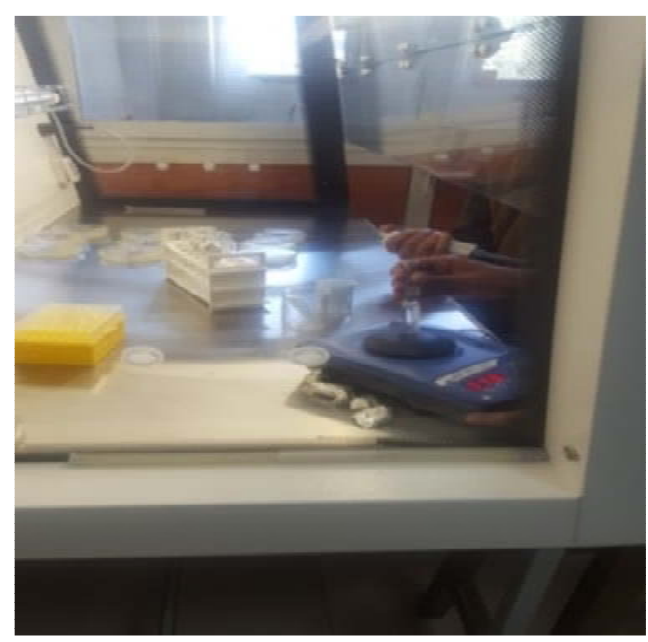

Figure 2. Dilution of waste water sample.

\subsubsection{Plating}

1) $0.1 \mathrm{ml}$ of diluted sample was taken from each of 12 test tubes and inoculated into labeled agar plate (inoculation of the sample occur after agar solution were solidified on plate. This solidification processes may be take up to $20 \mathrm{~min}$ )

2) Then by using sterilized spreader the sample was distributed.

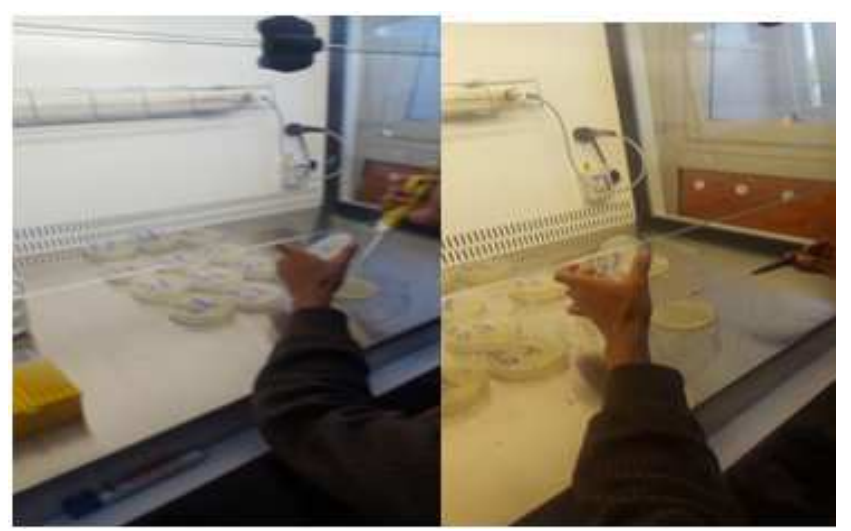

Figure 3. Inoculation of diluted sample and spreading over the agar plate solution.

3) Then finally took all the prepared Petri dishes into incubator at $25^{\circ} \mathrm{C}$ and inspected after 24,48 or 72 hours.

4) After $24 \mathrm{hr}$ of incubation, convert the other sides of plate (i.e. the smaller size of plate putted on upper side) to remove water.

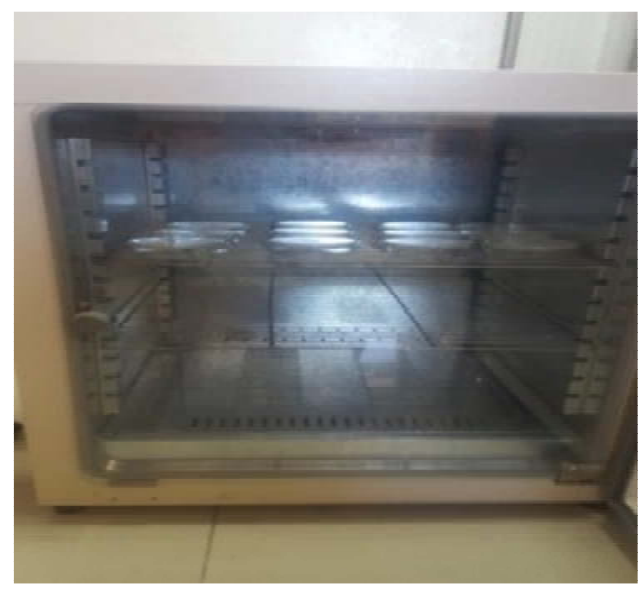

Figure 4. Incubation.

\section{Waste Water Treatment}

\subsection{Nutrient Broth Preparation}

$6.50 \mathrm{~g}$ of nutrient broth (3.25 $\mathrm{g}$ for each deep and surface) was weighted added into $250 \mathrm{ml}$ of distilled water of two 500 ml flask.

The $10^{-6}$ and $10^{-5}$ deep and surface cultivated colonies respectively were taken from incubated Petri dish by loop and added into nutrient broth solution and again covered with aluminum foil and cotton. Then the mixture was putted on shaker and left for 24 hours to allow microbial growth.

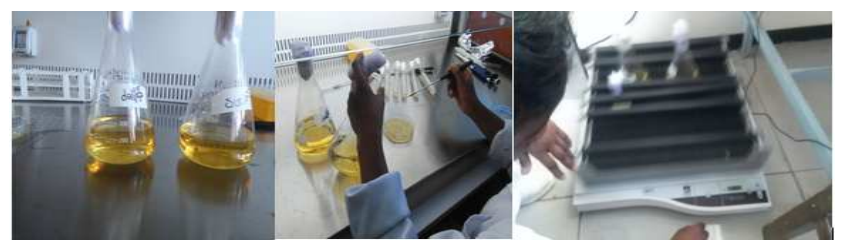

Figure 5. Sterilized nutrient broth solution, transferring colonies into nutrient broth solution and shaking it.

\subsection{Inoculation of Microorganism to Waste Water}

1) The deep and surface waste water from wolkite kera sefer jeblow meda was taken

2) $1 \%, 3 \%$ and $5 \%$ by volume of wastewater sample were taken and added into well prepared nutrient broth solution with transferred colonies

3) Then within 12 hours difference the color was checked and analysis physiochemical analysis the water.

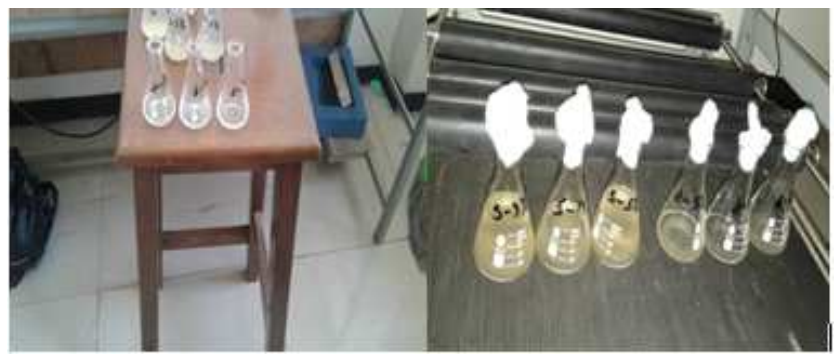

Figure 6. Before and after inoculation of the culture of microorganism into waste water. 


\section{Result and Discussion}

\subsection{Physiochemical Analysis of Sample Water Surface and Inner Collected (Case-1)}

Table 1. Physicochemical analysis of sample.

\begin{tabular}{lll}
\hline Name of chemicals and parameters & $\begin{array}{l}\text { Value of parameter obtained from surface collected } \\
\text { sample (M/l) }\end{array}$ & $\begin{array}{l}\text { Value of parameter obtained from inner } \\
\text { collected sample (M/l) }\end{array}$ \\
\hline $\mathrm{Ca}$ & 30.3 & 50.87 \\
$\mathrm{TDS}$ & 321 & 534 \\
$\mathrm{Na}$ & 34 & 87.5 \\
$\mathrm{~K}$ & 78 & 181.3 \\
$\mathrm{Cl}$ & 80 & 111 \\
$\mathrm{Bicarbonate} \mathrm{CaCO}_{3}$ & 120 & 432 \\
$\mathrm{Mg}$ & 28 & 212 \\
$\mathrm{~F}$ & 23 & 24 \\
$\mathrm{Total}$ iron & 2 & 3.5 \\
$\mathrm{NO}_{3}$ & 5 & 33 \\
$\mathrm{Total}$ alkality & 67 & 30.5 \\
$\mathrm{PH}$ & 3.0 & 4 \\
$\mathrm{SO}_{4}$ & 20 & 97.3 \\
\hline
\end{tabular}

The microbes in size, shape and, the cell number is count using eye, microscope, and atomic test or indirectly by determination of turbidity. It is important that the numbers of colonies developing on the plates are not being too large. On crowded plates some cells may not form colonies, and some colonies may fuse, leading to erroneous measurement Thus, to obtain the appropriate colony number, the samples need to be diluted. By using wire loop, the samples were spread into nutrient agar plate and the microbes were grown on it. From the observation, these samples take about 48 to 72 hours to growth on the plate. The result shows that the dilution of $10^{-1}$ to $10^{-6}$ for deep and surface sample, the colonies are too many and difficult to count for the case of $10^{-1}$. This is because of the dilution factor decrease from $10^{-6}$ to $10^{-1}$ that is the colonies in $10^{-1}$ are more concentrated than $10^{-6}$. For Clear identification of microorganism type's microscope and even biochemical analysis are needed. Even if there is no any biochemical test that has been done for identification of the microorganisms, we just visualize the colony. As we surveyed literatures the growth of yeast or fungal colony can be shown within 18 to $24 \mathrm{hrs}$. and bacterial colony can take most probably three to four days. Therefore in our case from the point of view that the deficiency of lab facility, we concluded that it may probably is bacterial species.

As visualized by naked eye the sample taken from surface have more colonies than the deep one. So it is possible to conclude that the surface is more polluted than deep. The inoculated wastewaters have some color change. This is done using $10^{-6}$ and $10^{-5}$ for deep and surface respectively. The $1 \%$, $3 \%$ and $5 \%$ by volume of broth added into waste water of $49.5 \mathrm{ml}, 48.5 \mathrm{ml}$ and $47.5 \mathrm{ml}$ respectively. This means that for $50 \mathrm{ml}$ of conical flask we are taken $0.5 \mathrm{ml}, 1.5 \mathrm{ml}$ and 2.5 $\mathrm{ml}$ of broth for $1 \%, 3 \%$, and $5 \%$ respectively. As the colonies of culture increase the probability of waste water to be clear is high.

\subsection{Physiochemical Analysis of Sample Water $10^{-5}$ and $10^{-6}$ Broths Prepared Companied Form (Case-2)}

Table 2. Physiochemical analysis of treated water with $10^{6}$ and $10^{5}$ microbes.

\begin{tabular}{llll}
\hline Name of chemical/parameter & $\mathbf{1 \%}$ broth inoculation $\mathbf{4 9 . 5} \mathbf{~ m l ~ o f ~ w w ~}$ & $\mathbf{3 \%}$ broth inoculation $\mathbf{4 8 . 5} \mathbf{~ m l ~ o f ~ w w ~}$ & $\mathbf{5 \%}$ broth inoculation $\mathbf{4 7 . 5} \mathbf{M l}$ of ww \\
\hline $\mathrm{Ca}$ & 19.3 & 12.87 & 9.87 \\
$\mathrm{Tds}$ & 192 & 106.75 & 67 \\
$\mathrm{Na}$ & 22.25 & 18.4 & 5 \\
$\mathrm{~K}$ & 44 & 33.14 & 1.14 \\
$\mathrm{Cl}$ & 70.5 & 45.4 & 2.69 \\
$\mathrm{Bicarbonate} \mathrm{CaCO}_{3}$ & 111 & 79.4 & 58.8 \\
$\mathrm{Mg}$ & 24 & 16.3 & 4.6 \\
$\mathrm{~F}$ & 14.4 & 8.25 & 0.45 \\
Total iron & 1.1 & 0.89 & 0.03 \\
$\mathrm{NO}_{3}$ & 3.25 & 1.78 & 0.98 \\
$\mathrm{Total}$ alkality & 33.7 & 30.9 & 30.5 \\
$\mathrm{PH}$ & 6.0 & 6.3 & 7.02 \\
$\mathrm{SO}_{4}$ & 10.9 & 7.4 & 3 \\
\hline
\end{tabular}




\section{3. $10^{-5}$ Broths Prepared Alone (Case-3)}

Table 3. Physiochemical analysis of treated water with $10^{5}$ microbes.

\begin{tabular}{|c|c|c|c|}
\hline $\begin{array}{l}\text { Name of } \\
\text { chemical/parameter }\end{array}$ & $1 \%$ broth inoculation $(49.5 \mathrm{ml})$ of $\mathrm{ww}$ & $3 \%$ broth inoculation $(48.5 \mathrm{ml})$ of ww & $5 \%$ broth inoculation with (47.5) Ml of ww \\
\hline $\mathrm{Ca}$ & 30.3 & 30.87 & 30.14 \\
\hline Tds & 321 & 319 & 320 \\
\hline $\mathrm{Na}$ & 34 & 33.2 & 33.5 \\
\hline $\mathrm{K}$ & 78 & 78 & 77.8 \\
\hline $\mathrm{Cl}$ & 80 & 78 & 76 \\
\hline Bicarbonate $\mathrm{CaCO}_{3}$ & 120 & 118 & 119.34 \\
\hline $\mathrm{Mg}$ & 28 & 28 & 28 \\
\hline $\mathrm{F}$ & 23 & 23 & 23 \\
\hline Total iron & 2 & 1.94 & 2 \\
\hline $\mathrm{NO}_{3}$ & 5 & 5 & 4.8 \\
\hline Total alkality & 67 & 68.2 & 67.6 \\
\hline $\mathrm{PH}$ & 3.0 & 4.1 & 2.78 \\
\hline $\mathrm{SO}_{4}$ & 20 & 19.5 & 18 \\
\hline
\end{tabular}

\section{4. $10^{-6}$ Broths Prepared Alone (Case-4)}

Table 4. Physiochemical analysis of treated water with $10^{6}$ of microbes.

\begin{tabular}{llll}
\hline Name of chemical/parameter & $\mathbf{1 \%}$ broth inoculation $\mathbf{4 9 . 5}$ of ww & $\mathbf{3 \%}$ broth inoculation $\mathbf{4 8 . 5} \mathbf{~ m l ~} \mathbf{~ o f ~} \mathbf{w w}$ & $\mathbf{5 \%}$ broth inoculation of $\mathbf{4 7 . 5} \mathbf{~ M l ~ o f ~} \mathbf{w w}$ \\
\hline $\mathrm{Ca}$ & 19.3 & 12.87 & 11.9 \\
$\mathrm{Tds}$ & 192 & 107 & 101.5 \\
$\mathrm{Na}$ & 22.25 & 18.4 & 18 \\
$\mathrm{~K}$ & 44 & 33.14 & 28.9 \\
$\mathrm{Cl}$ & 70.5 & 45.4 & 43.1 \\
$\mathrm{Bicarbonate} \mathrm{CaCO}_{3}$ & 111 & 79.8 & 65 \\
$\mathrm{Mg}$ & 24 & 16.6 & 14.3 \\
$\mathrm{~F}$ & 14.4 & 8.45 & 7.93 \\
$\mathrm{Total}$ iron & 1.1 & 0.95 & 0.61 \\
$\mathrm{NO}_{3}$ & 3.25 & 1.98 & 1.54 \\
$\mathrm{Total}$ alkality & 33.7 & 31.5 & 28.3 \\
$\mathrm{PH}$ & 6.0 & 6.1 & 7.3 \\
$\mathrm{SO}_{4}$ & 10.9 & 7.78 & 7.12 \\
\hline
\end{tabular}

We compare with wow natural spring water produced by wow share company in Ethiopia the parameter relatively similar with case 1 and case 3 mention with table 1 . And table 3 respectively (http://www.wow.org.et).

\section{Conclusion}

1) We concluded that from sample preparation surface and inner chemical composition some of heavy metals and performing reaction with halides by forming salts its obtained inner part of water sample because of precipitated at the bottom shown in case- 1 table.

2) As visualized by naked eye the sample taken from surface has more colonies (microbes) than the deep one. so it is possible to conclude that the surface is more polluted than deep in case of dissolved organic matter suspended at the surface so microbes can be used as substrate and free atmospheric air free obtained.

3 ) According to case-2 we conclude that there is combination of colonies we use the variation of chemical composition occurred that shows the availability of that have the potent of treat waste water.

4) Based on case-3 that microbes/colonies have no potent of treat contaminate because of litter variation between them

5) Case-2 the colonies has the potential to treat contaminate through them especially $5 \%$ of combined broth has to been treated up to level of drinking.

\section{Recommendation}

The recommendation for further researcher should be;

1) Researcher should authenticate, Affirmation and verification of those microbes by advanced biochemical and absorbance test especially who are those microbes.

2) Found out and characterize those microbes with other environmental sample rather pond water self for selfpurposed.

3) Develops other new substrate/nutrient agar for those microbes that can be more economical recommend for application. 


\section{References}

[1] Asano, Y., Komeda. T. \& Yamada. H. Microbial production of theobromine from caffeine. Bioscience Biotechnology Biochemistry, v. 57, p. 1286-1289, 1993.

[2] Blecher R, Lingens F. The metabolism of caffeine by a Pseudomonas putida strain. Hoppe-Seyler's Z Physiol Chem. 1997; 358: 807-17.

[3] Buerge IJ, Poiger T, Muller MD, Buser HR. Caffeine, an anthropogenic marker for wastewater contamination of surface water, Environ Sci Technol, 2003; 37: 691-700.

[4] Camargo MCR, Toledo MCF Caffeine content of commercial Brazilian coffee Cienc Technol Aliment. 1998; 18: 421-4.

[5] Dash SS, Gummadi SN. Biodegradation of caffeine by Pseudomonas sp. NCIM 5235, Research Journal of Microbiology. 2010; 5 (8): 745-753.

[6] EU COM (2011) 808: Horizon 2020 (2011). The framework programmed for Research and Innovation. EU, Brussels.

[7] Europaisches A. In: Coffeinum Theophyllinum, Deutscher Apotheker Verlag, Stuttgart; 1978, 670-121.

[8] Glassmeyer ST, Furlong ET, Kolpin DW, Cahill JD, Zaugg SD. Transport of chemical and microbial compounds from known waste water discharge: Potential for use as indicators of human fecal contamination, Environ Sci Technol, 2005; 39: 5157-5169.

[9] Mussatto, S. I., \& Roberto, I. C. (2005). Acid hydrolysis and fermentation of breweres spent grain to produce xylitol. Journal of the Science of Food and Agriculture, 85, 24532460 .

[10] Mussatto, S. I., \& Teixeira, J. A. (2010). Increase in the fructooligosaccharides yield and productivity by solid-state fermentation with Aspergillus japonicus using agro-industrial residues as support and nutrient source. Biochemical Engineering Journal, 53, 154-157.

[11] Punj S, editors. Abiotic stress: new research. Hauppauge, NY: Nova science publishers Inc: 2012. pp. 1-57.

12] Rawel, H. M., \& Kulling, S. E. (2007). Nutritional contribution of coffee, cacao and tea phenolics to human health. Journal of Consumer Protection and Food Safety, 2, 399-406.

[13] R. Losco and J. Valentine, "Storm water Infiltration and the Soil Landscape Connection," Pennsylvania Association of Professional Soil Scientists. 2003.

[14] http://www3.villanova.edu/vusp/Outreach/pasym03/pdfs/ 3A3.pdf

[15] Salihu Ibrahim, Mohd Yunus Shukor, Mohd Arif Syed, Nor Arina Ab Rahman, Khalilah Abdul Khalil, Ariff Khalid et al. Bacterial degradation of caffeine: a Review. Asian Journal of Plant Biology. 2014; 2 (1): 18-27.

[16] S. Clark and R. Pitt, "Storm water Runoff Treatment: Evaluation of Filtration Media," US Environmental Protection Agency, Water Supply and Water Resources Division, National Risk Management Research Laboratory, EPA No. 600R00010, Cincinnati, 1999.

[17] Nutrient management system. Can J Microbiol. 2008: 54; 876886. doi: 10. 1139/W08-081. [PubMed] [Cross_Ref].

[18] International Organization for Standardization (ISO) Standard 9000: 2005. Quality management system-fundamental and vocabulary. ISO, Switzerland, pp 1.

[19] https://en.wikipedia.org/wiki/Bacteria

[20] http://www.countyofdane.com/lwrd/landconservation/papers/i mpactsofswinfiltration.pdf

[21] Wang, D., Sakoda, A., \& Suzuki, M. (2001). Biological efficiency and nutritional value of Pleurotus ostreatus cultivated on spent beer grain. Bioresource Technology, 78, 293-300.

[22] Yamoka-Yano DM, Mazzafera P. Degradation of caffeine by pseudomonas putida isolated from soil. Allel J 1998; 5: 23-34.

[23] Zhuang, X. L., Zhang, H. X., Yang, J. Z., \& Qi, H. Y. (2001). Preparation of levoglucosan by pyrolysis of cellulose and its citric acid fermentation. Bioresource Technology, 79, 63-66. 